\title{
Classification of the Genus Mobiluncus Based on Comparative Partial 16S rRNA Gene Analysis
}

\author{
A. TIVELJUNG, U. FORSUM, ${ }^{*}$ AND H.-J. MONSTEIN \\ Department of Clinical Microbiology, Molecular Biology Laboratory, \\ University Hospital, S-581 85 Linköping, Sweden
}

\begin{abstract}
On the basis of partial $16 \mathrm{~S}$ rRNA gene sequences and the results of Southern blot analyses, we confirmed the division of the genus Mobiluncus into the species Mobiluncus curtisii and Mobiluncus mulieris. Division of $M$. curtisii into $M$. curtisii subsp. curtisii and $M$. curtisii subsp. holmesii was not supported by our data.
\end{abstract}

Spiegel and Roberts (15) proposed that the genus Mobiluncus comprises two distinct species, Mobiluncus curtisii and Mobiluncus mulieris, and these investigators also suggested that $M$. curtisii should be separated into $M$. curtisii subsp. curtisii and M. curtisii subsp. holmesii, a distinction that is still a matter of debate. The phylogenetic position of the genus Mobiluncus based on partial $16 \mathrm{~S}$ rRNA sequences was determined later (8), and it has been suggested that the genus Mobiluncus belongs to the order Actinomycetales.

However, characterization of $M$. curtisii and $M$. mulieris that are not type strains is a troublesome task since the phenotypes of both species vary. Identification of Mobiluncus strains has been based on morphological and biochemical characteristics (14), but proper identification sometimes is not possible because of phenotypic complexity. To improve species characterization, serological and nucleic acid methods have been used to supplement the classical methods (14). Neither polyclonal and monoclonal antibodies, nor nucleic acid hybridization in which genomic DNA probes are used, nor dot blot assays based on Mobiluncus-specific 16S rRNA sequences have substantially improved Mobiluncus classification.

The presence of evolutionarily conserved regions and variable sequence motifs within bacterial 16S rRNA genes has turned out to be valuable for microorganism identification. Gray et al. (7) identified eight universal regions and nine variable regions within the $16 \mathrm{~S}$ rRNA gene, and workers have shown that unculturable bacteria can be detected by using bacterial broad-range PCR primers based on conserved $16 \mathrm{~S}$ ribosomal DNA (rDNA) sequence motifs (13).

To further clarify the relationship between $M$. curtisii and $M$. mulieris and to determine whether the differentiation of $M$. curtisii subspecies is manifested evolutionarily within the $16 \mathrm{~S}$ rRNA gene, we performed a comparative sequence analysis of partial $16 \mathrm{~S}$ rDNA sequences. In addition, we constructed $M$. curtisii-specific DNA hybridization probes by using variable motifs within the 16S rRNA gene in order to establish a method which can be used to discriminate between $M$. curtisii and $M$. mulieris.

Practical approach. The Mobiluncus strains (Table 1) used in this study were cultured as described previously (6). DNA was extracted by the modified procedure of Woo et al. (19). Briefly, this modified method includes treatment with Triton $\mathrm{X}-100$, proteinase $\mathrm{K}$, lysozyme, and RNase and a final phenolchloroform extraction. Bacterial DNA was amplified by using Promega PCR reagents (Promega Corp., Madison, Wis.) and 200 pmol of primers pJB-1 and P13B, respectively, or 200 pmol of primers Mob-s and Mob-as, respectively (Table 2). The

\footnotetext{
* Corresponding author. Fax: 4613224596.
}

following PCR conditions were used: $94^{\circ} \mathrm{C}$ for $2 \mathrm{~min}, 60^{\circ} \mathrm{C}$ for $1 \mathrm{~min}$, and $72^{\circ} \mathrm{C}$ for $1 \mathrm{~min}(1 \mathrm{cycle}) ; 94^{\circ} \mathrm{C}$ for $20 \mathrm{~s}, 60^{\circ} \mathrm{C}$ for 20 $\mathrm{s}$, and $72^{\circ} \mathrm{C}$ for $20 \mathrm{~s}$ ( 29 cycles); and a final extension step consisting of $72^{\circ} \mathrm{C}$ for $10 \mathrm{~min}$. Subsequently, the PCR products were purified and the DNA sequences were determined by using the primers described in Table 2 and established standard procedures (commercial kits).

Southern blot analysis. The PCR products were separated on a $1.5 \%$ agarose gel, blotted onto a Hybond-N membrane (Amersham Corp.), and finally hybridized with 5 '-end-labelled broad-range primer pJB-1 or $M$. curtisii-specific primers MobV3 and Mob-V4 by using [ $\left.\gamma-{ }^{32} \mathrm{P}\right] \mathrm{ATP}(3,000 \mathrm{Ci} / \mathrm{mmol}$; Amersham Corp.) and a commercially available 5 -end-labelling kit (Boehringer Mannheim GmbH, Mannheim, Germany). The posthybridization treatment of the filter is described in the legend to Fig. 1. The membrane was exposed to type MP X-ray film (Amersham Corp.) at $-70^{\circ} \mathrm{C}$ for 5 to 24 h. After each hybridization experiment the hybridized primer was stripped off the membrane by boiling it for $2 \mathrm{~min}$.

Using Mobiluncus-specific PCR primers (8) which covered variable regions $\mathrm{V} 6, \mathrm{~V} 7$, and $\mathrm{V} 8$ according to the nomenclature of Gray et al. (7), we were able to amplify genomic rDNAs from Mobiluncus strains, including atypical strains A294, A345, A543, and 30185, as indicated in Table 1 . However, the genomic rDNA of atypical strain 0960 was not amplified. A DNA sequence analysis of the $\sim 400$-bp PCR products of type strains ATCC 35241, ATCC 35242, and ATCC 35243 revealed a 1-base transition ( $\mathrm{G}$ to $\mathrm{A}$ ) at position 755 when we compared $M$. curtisii and $M$. mulieris (all positions are the positions in the Escherichia coli 16S rRNA sequence [1]). No detectable DNA sequence differences were found in $M$. curtisii strains at the subspecies level.

Broad-range PCR amplification of Mobiluncus strains listed in Table 1 with PCR primers pJB-1 and p13B, which covered variable regions $\mathrm{V} 3, \mathrm{~V} 4$, and $\mathrm{V} 9$, yielded a $\sim 450$-bp product with all of the Mobiluncus strains tested. Direct DNA sequencing was performed by using the same primers. An alignment of the $16 \mathrm{~S}$ rDNA sequences revealed that there was distinct variability within motifs V3 and V4 of $M$. curtisii and $M$. mulieris, but no base deviations were found elsewhere in the $\sim 370$-bp sequence obtained. The sequences of variable regions $V 3$ and V4 of $M$. curtisii ATCC $35241^{\mathrm{T}}$ ( $\mathrm{T}=$ type strain), ATCC $35242^{\mathrm{T}}$, CCUG 21018 ${ }^{\mathrm{T}}$, CCUG $17762^{\mathrm{T}}, 1,3,8,9,2507,79363$, A63, Vib 7, Vib 16, M101f, M136-23, M119-3, L796, and L904c were determined by using sense primer pJB-1. The DNA sequences of type strains were also determined by using antisense primer p13B. We observed variability in the V3 region between positions 1006 and 1008 , where the $M$. curtisii DNA sequence had a base insertion. Another hypervariable motif in variable region V3 was also localized; $M$. curtisii ATCC $35241^{\mathrm{T}}$ 
TABLE 1. Mobiluncus strains used in this study and results obtained in Southern blot analyses when $M$. curtisiispecific hybridization probes were used



${ }^{a}$ See reference 6.

${ }^{b}$ The preparation was washed three times $(20 \mathrm{~min}$ each $)$ with $2 \times \mathrm{SSC}-0.1 \%$ sodium dodecyl sulfate at $50^{\circ} \mathrm{C}(1 \times \mathrm{SSC}$ is $0.15 \mathrm{M} \mathrm{NaCl}$ plus $0.015 \mathrm{M}$ sodium citrate $)$.

c The preparation was washed three times $\left(20 \mathrm{~min}\right.$ each) with $0.1 \times \mathrm{SSC}-0.1 \%$ sodium dodecyl sulfate at $50^{\circ} \mathrm{C}$.

${ }^{d}+$, positive; - , negative.

"Strain shown to be an $M$. curtisii strain in this study.

${ }^{f}$ Strain shown to be an atypical Mobiluncus strain in this study.

${ }^{g}$ Strain shown to be an $M$. mulieris strain in this study.

${ }^{h}$ Strain not identified in this study.

and ATCC $35242^{\mathrm{T}}$ had the DNA sequence motif $5^{\prime}-\mathrm{GCCA}-\mathrm{G}$ CCTTCG-3' between positions 1021 and 1032 (Fig. 2, box II). In variable region $\mathrm{V} 4, M$. curtisii had the DNA sequence motif 5'-G-GTTCGGCC-3' at positions 1133 to 1141 (Fig. 2, box III). Most strains that have been characterized by other workers as $M$. curtisii strains had these DNA sequence motifs in regions V3 and V4; the exceptions were strains 1,8 , and 9. Strain 1 of $M$. curtisii had an $M$. mulieris-like DNA sequence pattern, and strain 8 appeared to be unrelated to $M$. curtisii. Strain 8 was isolated from an external ear exudate (6). Strain 9 exhibited sequence variability identical to that exhibited by atypical Mobiluncus sp. strain 0960 (see below).

The DNA sequences of the PCR products of $M$. mulieris ATCC $35243^{\mathrm{T}}$, CCUG 20076 ${ }^{\mathrm{T}}, 1005,12158$, PG491, PG632, L33, M101a, M142-3, BV108-27, and L2313 were determined as described above for $M$. curtisii strains. The DNA sequence of strain ATCC $35243^{\mathrm{T}}$ spanning part of variable region V3 (positions 1021 to 1032 ) was $5^{\prime}$-TGTG-GCCTTCG-3' (Fig. 2, box II), and the DNA sequence 5'-ACGTTATGGT-3' (Fig. 2, box III) was found in variable region V4 (positions 1133 to 1141) (bases that differ from the bases in the $M$. curtisii DNA sequence are underlined). Most $M$. mulieris strains had the same DNA sequence as strain ATCC $35243^{\mathrm{T}}$; the exceptions were strains L33, M101a, and L2313, all of which had a DNA sequence identical to the $M$. curtisii sequence.

Mobiluncus sp. strains 0960, 30185, 90061, 15.18, 36.6, A294, A345, A543, and 01466.1, which were previously classified as atypical Mobiluncus strains, were also subjected to broad-range PCR amplification and subsequent DNA sequencing. Interestingly, strains 90061, A294, A345, A543, and 01466.1 had the 


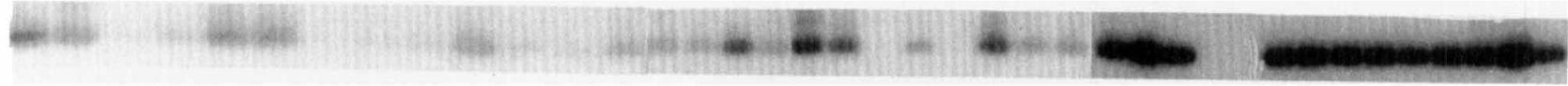

C



D

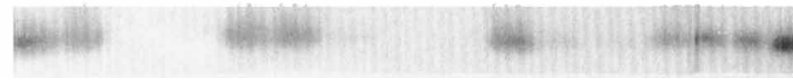

FIG. 1. Southern blot analyses of broad-range amplified PCR products from Mobiluncus strains. (A) Membranes were hybridized with 5'-end-labelled probe pJB-1 and then washed three times ( $20 \mathrm{~min}$ each) with $2 \times \mathrm{SSC}-0.1 \%$ sodium dodecyl sulfate at $50^{\circ} \mathrm{C}(1 \times \mathrm{SSC}$ is $0.15 \mathrm{M} \mathrm{NaCl}$ plus $0.015 \mathrm{M}$ sodium citrate). (B and C) After the hybridized probe was stripped off, the membranes were rehybridized with $5^{\prime}$-end-labelled $M$. curtisii-specific probe Mob-V3 and then washed three times (20 min each) with $2 \times \mathrm{SSC}-0.1 \%$ sodium dodecyl sulfate at $50^{\circ} \mathrm{C}(\mathrm{B})$ and three times $\left(20\right.$ min each) with $0.1 \times \mathrm{SSC}-0.1 \%$ sodium dodecyl sulfate at $50^{\circ} \mathrm{C}(\mathrm{C})$. (D) After the probe was stripped off, the membranes were finally rehybridized with $5^{\prime}$-end-labelled $M$. curtisii-specific probe Mob-V4 and washed three times ( 20 min each) with $2 \times$ SSC $-0.1 \%$ sodium dodecyl sulfate at $50^{\circ} \mathrm{C}$. The film was exposed at $-70^{\circ} \mathrm{C}$ overnight. The numbers at the top are the experiment numbers (see Table 1 ).

same DNA sequence as $M$. curtisii, but the DNA sequences of atypical strains 15.18 and 36.6 were $M$. mulieris-like. Only the sequences of atypical strains 0960 and 30185 differed from the $M$. curtisii and $M$. mulieris sequences in the broad-range amplified fragment. A similarity analysis (9) of aligned 16S rDNA sequences between positions 990 and 1360 revealed that the levels of sequence homology between the atypical strains and $M$. curtisii and $M$. mulieris strains were approximately $90 \%$. As shown in Fig. 2, strains 0960 and 30185 had homologous DNA sequences in variable region V4 (5'-AAGTTGTGTT-3'; positions 1133 to 1141 ) and in one of the hypervariable motifs in region V3 (5'-GTTTTCCTTTTT-3'; positions 1021 to 1032) (bases that differ from the bases in the $M$. curtisii DNA sequence are underlined). However, strains 0960 and 30185 exhibited sequence variability in the first hypervariable motif in region V3 (Fig. 2, box I), where they differed at two positions. Strain 9 of $M$. curtisii had the same DNA sequence as atypical strain 0960.

No base changes in the $\sim 370$-bp $16 \mathrm{~S}$ rDNA sequence were detected at the subspecies level in $M$. curtisii.

On the basis of the different DNA sequences in variable regions V3 and V4 of $M$. curtisii, $M$. mulieris, and atypical Mobiluncus strains, we constructed two $M$. curtisii-specific $16 \mathrm{~S}$ rRNA gene hybridization probes, Mob-V3 and Mob-V4. These probes were used to hybridize broad-range amplified $16 \mathrm{~S}$ rDNA products from Mobiluncus strains (Table 1). The PCR products were separated electrophoretically on an agarose gel, transferred to a Hybond-N membrane, and hybridized with
5 '-end-labelled broad-range primer pJB-1 (Fig. 1A). Then pJB-1 was stripped off by boiling the membrane in sterile water, and the filters were rehybridized with 5 -end-labelled probes Mob-V3 and Mob-V4; this was followed by a posthybridization treatment under moderately stringent conditions. Hybridization with Mob-V3 revealed that the probe was specific for the genus Mobiluncus, since it hybridized to all Mobiluncus strains listed in Table 1 except atypical strains 0960 and 30185 and $M$. curtisii 8 and 9 (Table 1 and Fig. 1B). More stringent posthybridization conditions resulted in higher levels of $M$. curtisii specificity of probe Mob-V3 since $M$. mulieris probes were removed (Table 1 and Fig. 1C). This species specificity of probe Mob-V3 was expected since the probe sequence derived from $M$. curtisii differs at four positions from the $M$. mulieris sequence. Hybridization with $5^{\prime}$-end-labelled probe Mob-V4 that differed at six positions from the $M$. $m u$ lieris sequence under moderately stringent conditions resulted in an $M$. curtisii-specific hybridization pattern (Table 1 and Fig. 1D). The differences in band intensity may have been due to multiple uses of the filters in hybridization experiments. However, in all cases classification of the strains analyzed was confirmed by DNA sequence data.

The level of DNA sequence homology between $M$. curtisii and $M$. mulieris in the Mobiluncus-specific amplified region was not consistent with previously published Mobiluncus $16 \mathrm{~S}$ rDNA sequence data, which indicated that the interspecies variation was greater (8). It is debatable whether a single base change in the Mobiluncus-specific region is enough to draw

TABLE 2. Oligodeoxyribonucleotide primers used for PCR amplification, to determine DNA sequences, and to hybridize $16 \mathrm{~S}$ rRNA genes of members of the genus Mobiluncus

\begin{tabular}{|c|c|c|c|c|}
\hline Primer & Sequence $\left(5^{\prime}\right.$ to $\left.3^{\prime}\right)$ & Specificity (orientation) & Position $^{a}$ & $T_{m}\left({ }^{\circ} \mathrm{C}\right)^{b}$ \\
\hline pJB-1 & ATTCGATGCAACGCGAAGAACCTTACC & Broad range (sense) & 959 & 54.6 \\
\hline p13B & GTGTACTAGGCCCGGGAACGTATTC & Broad range (antisense) & 1397 & 55.9 \\
\hline Mob-s & GTGAACTCCTTГTTCTCGTGAA & Mobiluncus specific (sense) & 452 & 45.3 \\
\hline Mob-as & CGCAGAAACACAGGATTGCATCC & Mobiluncus specific (antisense) & 855 & 51.9 \\
\hline Mob-V3 & GCCAGCCTTCGGGGTGGTGT & M. curtisii specific (sense) & 1021 & 54.9 \\
\hline Mob-V4 & TCACGAGTCCCCGGCCGAACC & M. curtisii specific (antisense) & 1153 & 57.0 \\
\hline
\end{tabular}

" 5 ' position in the Escherichia coli $16 \mathrm{~S}$ rRNA sequence (1)

${ }^{b}$ The melting temperature $\left(T_{m}\right)$ was calculated by using the following formula: $T_{m}=81.5+16.6\left(\log \left[\mathrm{K}^{+}\right]\right)+0.41(\mathrm{~mol} \% \mathrm{G}+\mathrm{C})-(675 / n)$, where $\left[\mathrm{K}^{+}\right]$is $0.050 \mathrm{M}$ and $n$ is the chain length (17) 


\begin{tabular}{|c|c|c|c|c|c|c|c|c|}
\hline \multirow[b]{3}{*}{ E.c., ATCC $25922^{\top}$} & \multirow[b]{2}{*}{998} & \multirow{2}{*}{\multicolumn{2}{|c|}{ I }} & \multirow[b]{2}{*}{ v3 } & \multicolumn{2}{|r|}{ Mob } & \multicolumn{2}{|r|}{3} \\
\hline & & & & & & II & & 1042 \\
\hline & $\mathrm{CCACGG}$ & A AG & T T T T & C A G A G A T G A & GA A T G & TGCCTTCG & GG A A C C & CGTGA \\
\hline M.m., ATCC $35243^{\top}$ & $\mathrm{A} \cdots \mathrm{T}-$ & $\mathrm{CGA}_{*}$ & $\mathrm{CA}$. & $\cdots$ & $-T G-$ & $\cdots$ & - GTG & $\cdots \mathrm{T}$ \\
\hline M.c.c., $\operatorname{ATCC} 35241^{\top}$ & $\mathrm{A}-\ldots \mathrm{T}-$ & CGA) & 160 & & $-\sec 1$ & $\cdots$ & $\ldots$ GT G & $\cdots \mathrm{T}$ \\
\hline M.c.h., ATCC $35242^{\top}$ & $\mathrm{A} \cdots \mathrm{T}-$ & CGA) & a d - & $\cdots$ & - Gec a & $\cdots$ & $\because$ GT G & $\cdots \mathrm{T}$ \\
\hline 0960. & G - . T - & G- C & CGA-C & $\ldots$. & $G T-T$ & $\mathrm{C}-\mathrm{T}-\mathrm{T} \mathrm{T}$ & $\therefore$ CTG & $\cdots \mathrm{T}$ \\
\hline 9 & $G-\ldots T-$ & G- C & $C G A-C$ & & $G T-T$ & $\mathrm{C}-\mathrm{T}-\mathrm{TT}$ & $\therefore$ CTG & $\cdots \mathrm{T}$ \\
\hline 30185 & G. - T - & G. C & T GG - $\mathrm{C}$ & - & $G T-T$ & $\mathrm{C}-\mathrm{T}-\mathrm{T} \mathrm{T}$ & - CTG & $\cdots \mathrm{T}$ \\
\hline
\end{tabular}

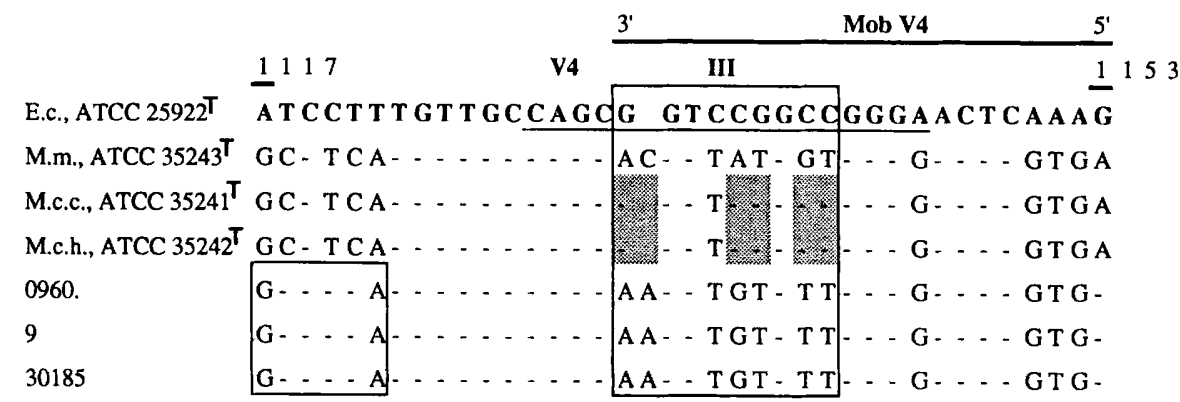

FIG. 2. Alignment of $16 \mathrm{~S}$ rRNA genes within variable regions V3 and V4 (underlined). Gaps indicate base deletions, and dashes indicate positions at which the sequence is homologous to the reference sequence ( $E$. coli $[1])$. The locations of the Mob-V3 and Mob-V4 oligonucleotide primers are indicated. Abbreviations: E.c., Escherichia coli; M.m., Mobiluncus mulieris; M.c.c., Mobiluncus curtisii subsp. curtisii; M.c.h., Mobiluncus curtisii subsp. holmesii. Strains 0960, 30185, and 9 are clinical isolates (Table 1). Boxes indicate DNA sequences which are different in different Mobiluncus strains (see text).

taxonomic conclusions. Instead, we focused on another part of the 16S rDNA sequences which were amplified with broadrange bacterial PCR primers pJB-1 and $\mathrm{p} 13 \mathrm{~B}$ and subsequently directly sequenced. The $16 \mathrm{~S}$ rDNA sequences of members of the genus Mobiluncus revealed that there were species differences in variable regions V3 and V4. Furthermore, $M$. curtisiispecific DNA hybridization probes were constructed from these variable regions to ensure proper identification of the genus Mobiluncus.

The genetic drift observed in variable regions V3 and V4 of the $16 \mathrm{~S}$ rDNA sequences supports the taxonomic division of members of the genus Mobiluncus into two distinct species, $M$. curtisii and $M$. mulieris. $M$. curtisii and $M$. mulieris exhibited base differences at 14 positions in these variable regions. The potential of our $M$. curtisii -specific hybridization probes, MobV3 and Mob-V4, was clearly demonstrated, and the data obtained with these probes supported this classification (Fig. 1). Hybridization with probe Mob-V3 resulted in specificity for the genus Mobiluncus under moderately stringent posthybridization conditions. More stringent posthybridization conditions resulted in specificity for $M$. curtisii. $M$. curtisil-specific probe Mob-V4 was discriminatory even under moderately stringent posthybridization conditions (Fig. 1). These probes did not react with other, non-Mobiluncus-related bacterial strains (data not shown). To show that clinical strains exhibited sequence homologies that were consistent with hybridization results, the DNA sequences of the $M$. curtisii strains collected from investigators around the world (6) and listed in Table 1 were determined in the sense direction; thus, variable regions V3 and V4 were included. The DNA sequence analysis results were consistent with the hybridization results.

The complexity of the genus Mobiluncus has forced some investigators to classify several Mobiluncus strains as atypical strains (Table 1). The strains described by Garlind et al. (6) were subjected to $16 \mathrm{~S}$ rDNA analyses and species-specific hybridization. Interestingly, strains 90061, A294, A345, A543 and 01466.1 had partial 16S rDNA sequences identical to those of $M$. curtisii strains. All of these strains except strain 01466.1 exhibited biochemical differences when they were compared with the $M$. curtisii type strains (6). Atypical strains 15.18 and 36.6 exhibited sequence homology to $M$. mulieris and also produced identical phenotypic patterns (6). Interestingly, atypical strain 30185, but not strain 0960, was amplified when these strains were subjected to Mobiluncus-specific PCR amplification. Atypical strains 0960 and 30185 exhibited a high level of homology, and significant sequence differences compared with Mobiluncus strains were detected, especially in variable regions $\mathrm{V} 3$ and V4 but also elsewhere in the partial 16S rDNA sequences.

Spiegel and Roberts (15) proposed that the members of $M$. curtisii should be separated into subspecies $M$. curtisii subsp. curtisii and $M$. curtisii subsp. holmesii on the basis of different migration patterns in soft agar and the ability of $M$. curtisii subsp. holmesii to reduce nitrate. Using a variety of techniques, other investigators had difficulty finding evidence which supported this proposal $(2,3,6,11,18)$. Unpublished data from workers in our group confirmed the nitrate-reducing properties of the American Type Culture Collection type strains. Vetere et al. (18) proposed that members of the genus Mobiluncus should be separated into more than two species, but their data did not support division of $M$. curtisii because all of the strains that were not type strains tested were nitrate reducers. Our $16 \mathrm{~S}$ rDNA sequence analyses revealed that the sequences of $M$. curtisii subsp. curtisii and $M$. curtisii subsp. holmesii are completely homologous, which is in conflict with the proposed division of $M$. curtisii into subspecies (15). How- 
ever, the conflicting genotypic and phenotypic results add a further argument to the discussion whether 16S rRNA gene sequences alone provide enough information to distinguish $M$. curtisii subspecies $(5,10,16)$. Fohn et al. (4) raised a series of monoclonal antibodies to $M$. curtisii subsp. curtisii and $M$. mulieris and found that at a 1/50 dilution of the culture fluids these antibodies could distinguish between $M$. curtisii subsp. curtisii and $M$. curtisii subsp. holmesii. These findings are not consistent with those of Påhlson et al., who were not able to distinguish between $M$. curtisii subsp. curtisii and $M$. curtisii subsp. holmesii with a set of monoclonal antibodies (11). No taxonomic conclusion can be drawn from the findings of Fohn et al. (4) since dilution experiment data are not reported for the various monoclonal antibodies. On the basis of DNA hybridization data and $\mathrm{G}+\mathrm{C}$ contents, Christiansen et al. suggested that the more homologous long curved rods (LCR) (M. mulieris) is a distinct species, but the more heterologous short curved rods (SCR) (M. curtisii) should be separated into several species (3). However, these authors felt that these species designations should be supported by biochemical and serological evidence.

Several investigators have described the phenotypic complexity of the genus Mobiluncus and have characterized several atypical Mobiluncus strains $(3,6,12,18)$. Spiegel stated that the differences are due mainly to differences in the media and methods used, as well as to normal strain variation (14). However, when partial 16S rDNA sequences were examined, no differences between $M$. curtisii subsp. curtisii and $M$. curtisii subsp. holmesii sequences were found. These results are not consistent with the previously described division of $M$. curtisii strains into subspecies, which was based on biochemical and serological results.

Nucleotide sequence accession numbers. Partial DNA sequences derived from broad-range amplified 16S rRNA genes have been deposited in the European Molecular Biology Laboratory Data Library under the following accession numbers M. mulieris ATCC $35243^{\mathrm{T}}$, X82602; $M$. curtisii subsp. curtisii ATCC $35241^{\mathrm{T}}$, X82603; $M$. curtisii subsp. holmesii ATCC 35242 ${ }^{\mathrm{T}}$, X82604; Mobiluncus sp. strain A294, X82605; Mobiluncus sp. strain A345, X82606; Mobiluncus sp. strain A543, X82607; and atypical Mobiluncus sp. strain 0960, X82608. Partial DNA sequences derived from Mobiluncus-specific amplified 16S rRNA genes have been deposited under the following accession numbers: $M$. mulieris ATCC $35243^{\mathrm{T}}$, X86004; M. curtisii subsp. curtisii ATCC $35241^{\mathrm{T}}$, X86005; and $M$. curtisii subsp. holmesii ATCC $35242^{\mathrm{T}}$, X86006.

This work was supported by the Molecular Biology Program, University Hospital, Linköping, Sweden, and the County of Östergötland Medical Research Foundation.
We thank Erik Kihlström for critical reading of and comments on the manuscript.

\section{REFERENCES}

1. Brosius, J., M. L. Palmer, P. J. Kennedy, and H. F. Noller. 1978. Complete nucleotide sequence of a $16 \mathrm{~S}$ ribosomal RNA gene from Escherichia coli. Proc. Natl. Acad. Sci. USA 75:4801-4805.

2. Carlone, G. M., M. L. Thomas, R. J. Arko, G. O. Guerrant, C. W. Moss, J. M. Swenson, and S. A. Morse. 1986. Cell wall characteristics of Mobiluncus species. Int. J. Syst. Bacteriol. 36:288-296.

3. Christiansen, G., E. Hansen, E. Holst, C. Christiansen, and P.-A. Mårdh 1984. Genetic relationships of short and long anaerobic curved rods isolated from the vagina, p. 75-78. In P.-A. Mårdh and D. Taylor-Robinson (ed.) Bacterial vaginosis. Almqvist and Wiksell International, Stockholm.

4. Fohn, M. J., S. A. Lukehart, and S. L. Hillier. 1988. Production and characterization of monoclonal antibodies to Mobiluncus species. J. Clin. Microbiol. 26:2598-2603.

5. Fox, G. E., J. D. Wisotzkey, and P. Jurtshuk, Jr. 1992. How close is close: 16S rRNA sequence identity may not be sufficient to guarantee species identity. Int. J. Syst. Bacteriol. 42:166-170.

6. Garlind, A., C. Påhlsson, and U. Forsum. 1989. Phenotypic complexity in Mobiluncus. APMIS 97:38-42.

7. Gray, M. W., D. Sankoff, and R. J. Cedergren. 1984. On the evolutionary descent of organisms and organelles: a global phylogeny based on a highly conserved structural core in small subunit ribosomal RNA. Nucleic Acids Res. 12:5837-5852

8. Lassnig, C., M. Dorsch, J. Wolters, E. Schaber, G. Stöffler, and E. Stackebrandt. 1989. Phylogenetic evidence for the relationship between the genera Mobiluncus and Actinomyces. FEMS Microbiol. Lett. 53:17-21.

9. Olsen, G. J. 1988. Phylogenetic analysis using ribosomal RNA. Methods Enzymol. 164:793-812.

10. Olsen, G. J., and C. R. Woese. 1993. Ribosomal RNA: a key to phylogeny FASEB J. 7:113-123.

11. Påhlson, C., A. Hallén, and U. Forsum. 1986. Curved rods related to Mobiluncus-phenotypes as defined by monoclonal antibodies. Acta Pathol. Microbiol. Immunol. Scand. Sect. B 94:117-125.

12. Påhison, C., J. G. Mattsson, P.-G. Larsson, H. Gersdorf, U. B. Göbel, U. Forsum, and K.-E. Johansson. 1992. Detection and identification of Mobiluncus species by direct filter hybridization with an oligonucleotide probe complementary to rRNA. APMIS 100:655-662.

13. Relman, D. A., T. M. Schmidt, R. P. MacDermott, and S. Falkow. 1992 Identification of the uncultured bacillus of Whipple's disease. N. Engl. J. Med. 327:293-301.

14. Spiegel, C. A. 1992. The genus Mobiluncus, p. 906-918. In A. Balows, H.-G. Trüper, M. Dworkin, W. Harder, and K. H. Schleifer (ed.), The prokaryotes, 2nd ed. Springer-Verlag, New York.

15. Spiegel, C. A., and M. Roberts. 1984. Mobiluncus gen nov., Mobiluncus curtisii subsp. curtisii sp. nov., Mobiluncus curtisii subsp. holmesii subsp. nov., and Mobiluncus mulieris sp. nov., curved rods from the human vagina. Int. J. Syst. Bacteriol. 34:177-184,

16. Stackebrandt, E, and B. M. Goebel. 1994. Taxonomic note: a place for DNA-DNA reassociation and $16 \mathrm{~S}$ rRNA sequence analysis in the present species definition in bacteriology. Int. J. Syst. Bacteriol. 44:846-849.

17. Stahl, D. A., and R. Amann. 1991. Development and application of nucleic acid probes, p. 205-212. In E. Stackebrandt and M. Goodfellow (ed.), Nucleic acid techniques in bacterial systematics. John Wiley \& Sons, Chichester, United Kingdorn.

18. Vetere, A., S. P. Borriello, E. Fontaine, P. J. Reed, and D. Taylor-Robinson. 1987. Characterisation of anaerobic curved rods (Mobiluncus spp.) isolated from the urogenital tract. J. Med. Microbiol. 23:279-288.

19. Woo, T. H. S., A. F. Cheng, and J. M. Ling. 1992. An application of a simple method for the preparation of bacterial DNA. BioTechniques 13:696-698. 